\title{
Mass Spectrometry-Based Comprehensive Analysis of Pancreatic Cyst Fluids
}

\author{
Agnieszka Paziewska, ${ }^{1}$ Marcin Polkowski, ${ }^{1}$ Tymon Rubel, ${ }^{2}$ \\ Jakub Karczmarski, ${ }^{3}$ Anna Wiechowska-Kozlowska, ${ }^{4}$ Michalina Dabrowska, ${ }^{3}$ \\ Michal Mikula $\mathbb{D}^{3},{ }^{3}$ Michal Dadlez, ${ }^{5}$ and Jerzy Ostrowski $\mathbb{D}^{1,3}$ \\ ${ }^{1}$ Department of Gastroenterology, Hepatology and Clinical Oncology, Medical Center for Postgraduate Education, Warsaw, Poland \\ ${ }^{2}$ Institute of Radioelectronics and Multimedia Technology, Warsaw University of Technology, Warsaw, Poland \\ ${ }^{3}$ Department of Genetics, Maria Sklodowska-Curie Memorial Cancer Center and Institute of Oncology, Warsaw, Poland \\ ${ }^{4}$ Department of Endoscopy, Ministry of Internal Affairs Hospital, Szczecin, Poland \\ ${ }^{5}$ Institute of Biochemistry and Biophysics, Polish Academy of Sciences, Warsaw, Poland
}

Correspondence should be addressed to Jerzy Ostrowski; jostrow@warman.com.pl

Received 27 April 2018; Accepted 18 November 2018; Published 29 November 2018

Academic Editor: Stanley Brul

Copyright (C) 2018 Agnieszka Paziewska et al. This is an open access article distributed under the Creative Commons Attribution License, which permits unrestricted use, distribution, and reproduction in any medium, provided the original work is properly cited.

\begin{abstract}
Pancreatic cyst fluids (PCFs) enriched in tumour-derived proteins are considered a potential source of new biomarkers. This study aimed to determine compositional and quantitative differences between the degradome and proteome of PCFs aspirated from different types of pancreatic cyst lesions (PCLs). 91 patients who underwent endoscopic ultrasound-fine needle aspiration under routine clinical diagnosis of PCLs were enrolled. Four cysts were malignant (CAs), and 87 were nonmalignant and consisted of 18 intraductal papillary mucinous neoplasms (IPMNs), 14 mucinous cystic neoplasms (MCNs), nine serous cystic neoplasms (SCNs), 29 pseudocysts (PCs), and 17 unclassified. Profiles of the $<5 \mathrm{kDa}$ fraction, the degradome, and the trypsin-digested proteome were analysed using an LTQ-Orbitrap Elite mass spectrometer coupled with a nanoACQUITY LC system. Qualitative analyses identified 796 and 366 proteins in degradome and proteome, respectively, and 689 (77\%) and 285 (78\%) of them were present in the Plasma Proteome Database. Gene Ontology analysis showed a significant overrepresentation of peptidases and peptidases inhibitors in both datasets. In the degradome fraction, quantitative values were obtained for 6996 peptides originating from 657 proteins. Of these, 2287 peptides were unique to a single type, and 515 peptides, derived from 126 proteins, were shared across cyst types. 32 peptides originating from 12 proteins had differential (adjusted $p$-value $\leq 0.05, \mathrm{FC} \geq 1.5$ ) abundance in at least one of the five cysts types. In proteome, relative expression was measured for 330 proteins. Of them, 33 proteins had significantly (adjusted $p$-value $\leq 0.05, \mathrm{FC} \geq 1.5$ ) altered abundance in at least one of the studied groups and 19 proteins appeared to be unique to a given cyst type. PCFs are dominated by blood proteins and proteolytic enzymes. Although differences in PCF peptide composition and abundance could aid classification of PCLs, the unpredictable inherent PCF proteolytic activity may limit the practical applications of PCF protein profiling.
\end{abstract}

\section{Introduction}

The prevalence of pancreatic cysts in different studied populations varies between $2 \%$ and $45 \%$ [1]. Clinically, they are categorised as nonneoplastic and neoplastic. The most common pancreatic nonneoplastic cysts are pseudocysts (PCs), while neoplastic cysts are represented by serous cystic neoplasms (SCNs), mucinous cystic neoplasms (MCNs), and intraductal papillary mucinous neoplasms (IPMNs) [1]. To recognise the cyst type, clinical presentation, and patient's age and sex, axial imaging based on computed tomography (CT) or magnetic resonance imaging (MRI) and endoscopic ultrasound-fine needle aspiration (EUS-FNA) results are combined in clinical practice [2]. However, the diagnostic accuracy of CT- and MRI-based imaging techniques ranges from $55 \%$ to $75 \%$ [1], while the sensitivity of cytological evaluation of cyst fluid is 
$\sim 50 \%$ for differentiation of pancreatic cyst lesions (PCLs) [3$5]$.

Advances in proteomic methodology have stimulated substantial interest for investigating PCF proteomes (reviewed in [6]), and a few potential candidate biomarkers have been reported, including olfactomedin-4, several mucins, two homologs of amylase, four solubilised carcinoembryonic antigen (CEA)-related cell adhesion molecules, four S100 homologs, and IL1 $\beta[2,7,8]$. In addition, glycan variants on mucin proteins appear to be particularly sensitive and specific for differentiating between mucinous cysts $[9,10]$, while high-mobility group (HMG) A2 protein is considered a dysplasia grade biomarker in IPMNs [11]. However, except for CEA and amylase, no other protein marker by itself is consistently reliable and sufficiently conclusive for diagnosing and risk-stratifying pancreatic cysts.

The biological nature of pancreatic cysts varies significantly because their fluids can be dense or diffuse, mucinous, or bloody, mixed together with the contents of pancreatic ducts or isolated from pancreatic proenzymes [8]. Based on type, pancreatic cyst fluids (PCFs) are divided into serous (containing a thin fluid) or mucinous (containing a viscous fluid). However, in contrast to the relatively constant composition of serum proteins, differences within proteomes from the same type of PCFs are apparent, making PCF proteomics challenging. One of the fundamental causes of these differences is the variable abundance and combination of pancreatic peptidases, including carboxypeptidases, aminopeptidases, and matrix metalloproteases. The proteolytic activity of these enzymes results in a constellation of peptides derived from major proteins (the degradome), and studying these peptides (degradomics) is likely to prove useful for PCF research.

To date, no single study has compared the degradome and proteome of PCFs. Herein, we present a qualitative and quantitative MS-based survey of the degradome and proteome of nonprotease inhibitors treated PCFs derived from clinically different cyst types.

\section{Materials and Methods}

2.1. Study Participants. The study protocol was accepted by the Ethical Review Board at the M. Skłodowska-Curie Memorial Cancer Centre and Institute of Oncology, Warsaw, Poland. The study was conducted according to the principles expressed in the Declaration of Helsinki and informed written consent was obtained from the participants. From March 2012 to November 2013, 91 patients were recruited at two large-volume EUS-centers: Department of Gastroenterology, M. Skłodowska-Curie Memorial Cancer Centre, Warsaw, Poland, and Department of Endoscopy, Ministry of Internal Affairs Hospital, Szczecin, Poland. Cyst fluids were collected prospectively and the analyses were performed as a part of routine diagnostic work-up. Inclusion criteria were as follows: (1) Patients aged 18 years or older. (2) A cyst larger than $15 \mathrm{~mm}$. (3) Written patient's informed consent for participating in the study. Exclusion criteria were as follows: (1). Known coagulation disorder (INR $>1,5, \mathrm{PTT}>50$ seconds, platelets $<50.000 / \mu \mathrm{L}$ ). (2) Being treated with acetylsalicylic acid and/or clopidogrel within 5 days.

EUS-FNA was performed by experienced endosonographers (MP, AWK) in standard fashion with a curvedlinear echoendoscope and $22 \mathrm{G}$ or $19 \mathrm{G}$ needles. The following PCL characteristics were recorded: cyst location, maximal diameter, and morphology: wall thickness, septations, calcifications, solid component, and mural nodules. An attempt at total aspiration of the cyst fluid was made whenever possible. Cyst fluids were analysed by standard diagnostic procedures (cytology, amylase, CEA, and viscosity), and rest of the aspirated fluids were aliquoted into Eppendorf tubes at $1 \mathrm{ml}$ volumes and stored at $-80^{\circ} \mathrm{C}$ within $30 \mathrm{~min}$ of harvesting. The protease inhibitors were not spiked-in to PCF upon collection. Targeted cyst wall punctures were performed at the endosonographer discretion. Prophylaxis with fluoroquinolones or betalaktam antibiotics was administered according to the European Society of Gastrointestinal Endoscopy guideline [13]. Patients were observed for at least two hours postprocedure.

2.2. Preparation of Cysts Fluid Samples for Peptidome Analyses. The LMW fraction of the PCFs was analysed as described previously for the plasma/serum peptidome [14]. Briefly, a mix of $100 \mu \mathrm{l} \mathrm{PCF}+300 \mu \mathrm{l} 25 \%$ acetonitrile in $25 \mathrm{mM} \mathrm{NH}_{4} \mathrm{HCO}_{3}$ was centrifuged at $5000 \mathrm{x} \mathrm{g}$, at $15^{\circ} \mathrm{C}$, for 90 minutes through a $30 \mathrm{kDa}$ cutoff filtration membrane (Millipore Ultrafree-MC, pore size 30000, Sigma-Aldrich), and then washed twice with $25 \%$ acetonitrile prior to use. Next, $100 \mu \mathrm{l} 25 \%$ acetonitrile was applied to the filter and again centrifuged for $60 \mathrm{~min}$. Finally, the combined filtrates were centrifuged at $5000 \mathrm{x} \mathrm{g}$, at $15^{\circ} \mathrm{C}$, for 120 minutes through the $5 \mathrm{kDa}$ cutoff filtration membrane (Millipore Ultrafree-MC, pore size 5000), and the $<5 \mathrm{kDa}$ fraction was lyophilized (Speed Vac) in siliconized microtubes (Clear-view Snap-Cap microtubes, size $1.5 \mathrm{~mL}$, low retention, Sigma-Aldrich) and stored at $-80^{\circ} \mathrm{C}$ for further use. Prior to LC-MS analysis, samples were dissolved in $0.1 \%$ trifluoroacetic acid (TFA). MS/MS data was acquired from pooled PCF samples prepared by combining $10 \mu \mathrm{l}$ of fluids belonging to given cyst type from the study samples.

2.3. Preparation of Cysts Fluid Samples for Proteome Analyses. Proteins were precipitated from equal amounts (by protein content) of PCF samples using the ProteoExtract ${ }^{\circledR}$ Protein Precipitation Kit (Calbiochem Cat. No. 539790) according to the manufacturer's protocol. Protein pellets were resuspended in $100 \mu \mathrm{l} 100 \mathrm{mM} \mathrm{NH}_{4} \mathrm{HCO}_{3}$, the protein concentrations were then measured by the BCA method (Pierce ${ }^{\mathrm{TM}} \mathrm{BCA}$ Protein Assay Kit) and aliquots equal to $20 \mu \mathrm{g}$ proteins were reduced in 5mM Tris-(2-carboxyethyl) phosphine (SigmaAldrich), alkylated with $8 \mathrm{mM}$ S-Methyl methanethiosulfonate (Sigma-Aldrich), then trypsin-digested (Sequencing Grade Modified Trypsin, Promega) using standard protocols, and finally acidified with 5\%TFA to $\mathrm{pH}=4$.

2.4. LC-MS Settings. LC-MS analysis was performed on a LTQ-Orbitrap Elite mass spectrometer (Thermo) coupled to a nanoAcquity (Waters) LC system as described before [15]. 
Qualitative LC-MS/MS analyses were carried out on pooled samples in data-dependent acquisition mode and peptide fragmentation was achieved by high-energy collision dissociation (HCD). To increase the number of peptide identifications, three LC-MS/MS runs were performed per pooled sample, each covering one of three ranges of $\mathrm{m} / z$ values: 300-600, 600-800, and 800-2000. Quantitative analyses of individual samples were performed using separate survey scan LC-MS runs with a $\mathrm{m} / \mathrm{z}$ measurement range of 300-2 000 and the same acetonitrile gradient settings as those used for the LC-MS/MS runs.

2.5. Qualitative MS Data Processing and Database Search. The MS/MS raw data files were submitted to Mascot Distiller (version 2.5.1, Matrix Science), and the subsequent peak lists were uploaded to the Mascot engine (version 2.4.1, Matrix Science) and searched against SwissProt Homo sapiens database (release 2016.01) supplemented with contaminant proteins sequences from the Repository of Adventitious Proteins (cRAP, http://www.thegpm.org/crap). In total, the database contained 20,233 target sequences, and the same number of reversed decoy records. The search parameters were as follows: enzyme specificity: semitrypsin for proteome samples, and none for the degradome; maximum number of missed cleavages (for proteome only): 1; protein mass: unrestricted; parent ions mass error tolerance: 5 ppm; fragment ions mass error tolerance: $0.01 \mathrm{Da}$; fixed modifications (for proteome only): Methylthio (C); variable modifications: Oxidation (M).

Statistical significance of identified peptides was calculated as previously described $[16,17]$. For proteome samples proteins represented by less than two peptides or identified by peptides matching other proteins were excluded from analysis. Proteins matching the same set of peptides were merged together into metaproteins clusters.

As a graphical representation of protease specificity in degradome samples Sequence Logo was used [18]. Peptides identified in the studied group of samples were aligned to corresponding proteins, and amino acids at positions flanking the location their $\mathrm{N}$ - and C-termini were recorded. Next sequence logos depicting relative frequencies of amino acids around cleavage sites were generated.

Mascot results processing was done using MScan software available at http://proteom.ibb.waw.pl/mscan. This software tool was also used for Sequence Logo generation.

2.6. Quantitative MS Data Processing. The quantitative MS data processing and peptides feature extraction procedure was described in detail in a previous study [9]. Logtransformed peptide abundances were normalized by fitting a robust locally weighted regression smoother (LOESS) between individual samples and a median pseudosample. LOESS is a well-established method of normalization, commonly used to minimize systematic bias and the effects of nonbiological sources of variation in microarray and proteomic datasets $[19,20]$. The parameters for the fit were established using a set of features that exhibited low variance in the nonnormalized data and then applied to the whole data set. In the case of proteome samples, the normalized peptidelevel data were rolled-up to relative protein abundances. The procedure used involved rescaling abundances of peptides that originated from the same protein to a common level, followed by computing their median value.

2.7. Statistical Analysis. For peptide and protein abundance comparisons a nonparametric resampling-based ANOVA (Analysis of Variance) test with the F-statistic was used. The resulting $p$-values were corrected for multiple hypothesis testing by the Benjamini-Hochberg procedure for controlling the false discovery rate (FDR) [21]. Only peptide or protein abundances with FDR-adjusted $p$-values $\leq 0.05$ and fold change (FC) values $\geq 1.5$ were considered significantly changed.

Unsupervised principal components analysis (PCA) was utilized to evaluate and visualize the relationships between cyst types. PCA was computed using singular values decomposition (SVD) of both quantitative datasets.

All statistical analyses were performed in MStat (available at http://proteom.ibb.waw.pl/) running in the MATLAB (MathWorks) environment.

2.8. Functional Analysis. Identified proteins were annotated with Gene Ontology (GO) terms using the Molecular Function GO-Slim from the PANTHER web service (version 13.1) [22]. The binomial test, implemented in PANTHER, was used to determine the statistical significance of under- or overrepresentation of GO terms, and the returned $p$-values were corrected for testing of multiple hypotheses with the Bonferroni method. Adjusted $p$-values less than or equal to 0.05 were considered significant.

\section{Results}

3.1. Patient and Cyst Characteristics. The cohort consisted of 91 patients who underwent EUS-FNA under routine clinical diagnosis of PCLs. Clinical features of patients, including general demographics, cyst characteristics, and the cyst fluid concentration of CEA and amylase, are summarised in Table 1. Based on surgical pathology or, in patients in whom PCLs were not resected, on clinical follow-up for at least 1 year, four PCLs were diagnosed as malignant (one invasive adenocarcinoma with cystic degeneration, two MCNs and one IPMN with high-grade dysplasia). The remaining 87 PCLs were nonmalignant, classified as mucinous (18 IPMNs and 14 MCNs) and nonmucinous (29 PCs and 9 SCNs), while 17 PCLs were unclassified (UNC). Sufficient cyst fluid was allocated for cytology and molecular analyses for all 91 patients, and fluid CEA and amylase were measured in 86 (94.5\%) PCLs. Cyst fluid concentrations of CEA and amylase are summarised in Figure 1.

Mucinous cysts are lined with endoderm-derived columnar epithelium that secretes CEA, whereas nonmucinous cysts are lined by simple nonendoderm-derived epithelium that produces little or no CEA [23]. CEA abundance is the single best indicator for discriminating the malignant potential of PCLs, which, depending on the established cutoff 
TABLE 1: Clinical characteristics of patients.

\begin{tabular}{|c|c|c|c|c|c|c|}
\hline Female/Male & $\begin{array}{c}\text { Cyst type } \\
\text { (presumptive } \\
\text { clinical diagnosis) }\end{array}$ & & $\begin{array}{c}\text { Age at } \\
\text { EUS-FNA }\end{array}$ & $\begin{array}{l}\text { Max. cyst diameter } \\
(\mathrm{mm})\end{array}$ & Fluid CEA (ng/ml) & $\begin{array}{l}\text { Fluid amylase } \\
\qquad(\mathrm{IU} / \mathrm{l})\end{array}$ \\
\hline \multirow{5}{*}{$14 / 15$} & \multirow{5}{*}{ PC } & mean & 56 & 47 & 54 & 61900 \\
\hline & & $\mathrm{SD}$ & 13.5 & 29.2 & 59.6 & 69537.8 \\
\hline & & median & 57 & 38 & 27.53 & 40000 \\
\hline & & $\min$ & 25 & 20 & 0.3 & 381 \\
\hline & & $\max$ & 81 & 150 & 211.17 & 301180 \\
\hline \multirow{5}{*}{$7 / 2$} & \multirow{5}{*}{ SCN } & mean & 56 & 39 & 23 & 149 \\
\hline & & $\mathrm{SD}$ & 18.2 & 13.2 & 67.0 & 225.9 \\
\hline & & median & 64 & 35 & 0.54 & 28 \\
\hline & & $\min$ & 21 & 24 & 0 & 10 \\
\hline & & $\max$ & 74 & 60 & 202 & 704 \\
\hline \multirow{5}{*}{$13 / 5$} & \multirow{5}{*}{ IPMN } & mean & 60 & 39 & 429 & 17338 \\
\hline & & $\mathrm{SD}$ & 11.4 & 24.4 & 482.8 & 21582.0 \\
\hline & & median & 63 & 35 & 236 & 2891 \\
\hline & & $\min$ & 37 & 15 & 19.31 & 182 \\
\hline & & $\max$ & 79 & 130 & 1435 & 62460 \\
\hline \multirow{5}{*}{$12 / 2$} & \multirow{5}{*}{$\mathrm{MCN}$} & mean & 62 & 45 & 5466 & 1154 \\
\hline & & $\mathrm{SD}$ & 12.5 & 21.8 & 5700.7 & 2122.5 \\
\hline & & median & 65.5 & 41.5 & 2931 & 130 \\
\hline & & $\min$ & 35 & 20 & 217.3 & 1 \\
\hline & & $\max$ & 74 & 100 & 18623 & 7106 \\
\hline \multirow{5}{*}{$13 / 4$} & \multirow{5}{*}{ UNC } & mean & 56 & 38 & 66 & 3266 \\
\hline & & $\mathrm{SD}$ & 13.4 & 17.6 & 174.3 & 12789.7 \\
\hline & & median & 60 & 38 & 4.03 & 117 \\
\hline & & $\min$ & 34 & 20 & 0.2 & 1 \\
\hline & & $\max$ & 77 & 80 & 720 & 52892 \\
\hline
\end{tabular}

PC, pseudocyst; SCN, serous cystic neoplasm; IPMN, intraductal papillary mucinous neoplasm; MCN, mucinous cystic neoplasm; UNC, unclassified.
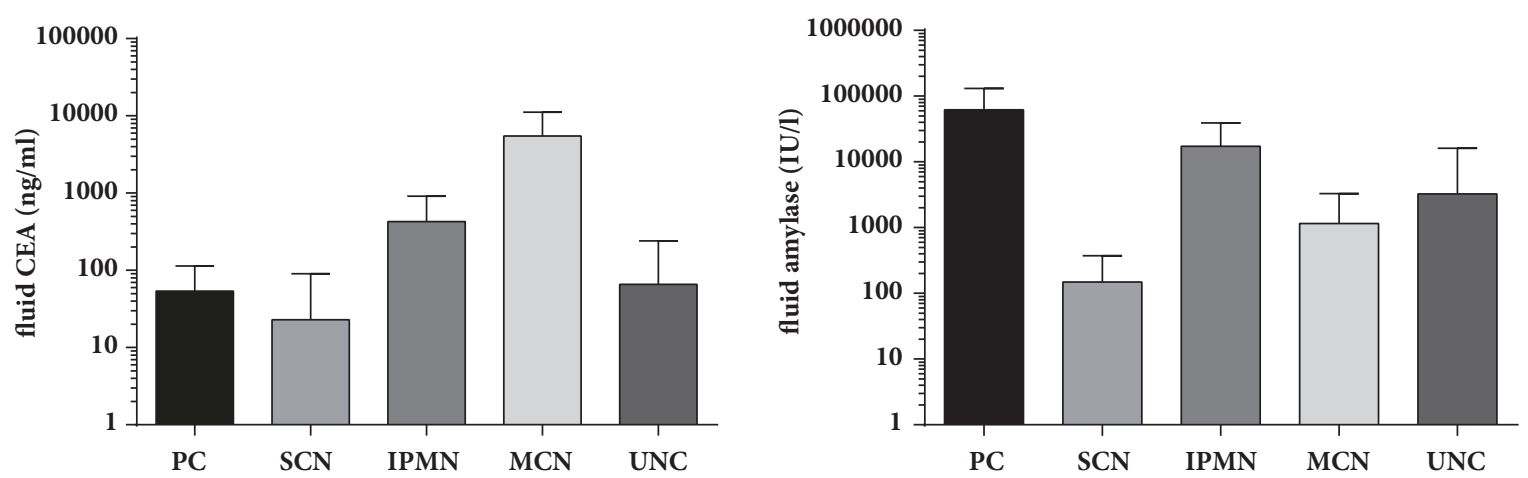

FIGURE 1: Comparison of cyst fluid carcinoembryonic antigen (CEA) and amylase levels in patients with pancreatic lesions (results presented on a logarithmic scale). Whiskers denote standard deviation. PC, pseudocyst; SCN, serous cystic neoplasm; IPMN, intraductal papillary mucinous neoplasm; MCN, mucinous cystic neoplasm; UNC, unclassified.

level, may reach a diagnostic accuracy of $80 \%$; hence it is considered the discriminatory method of choice for mucinous and nonmucinous PCLs [6, 7, 24, 25]. We confirmed that at a cutoff value of $192 \mathrm{ng} / \mathrm{mL}$, PCF CEA was moderately sensitive and highly specific for diagnosing all mucinous cysts $($ sensitivity $=81.2 \%$; specificity $=91.6 \%)$. The diagnostic accuracy of the test was $86.7 \%$, and the area under the curve (AUC) was 0.93.

High levels of cystic fluid amylase have been found in pancreatic cysts that communicate with pancreatic 
TABLE 2: Number of peptides detected in individual samples in the degradome dataset ( $<5 \mathrm{kDa}$ aspirated fraction). Numbers of proteins from which these peptides originate are indicated in parentheses.

\begin{tabular}{lcr}
\hline Cyst type & Peptides (proteins) & Peptides unique for group \\
\hline CA & $3224(463)$ & $660(267)$ \\
\hline SCN & $2724(353)$ & $302(128)$ \\
\hline MCN & $2175(334)$ & $117(73)$ \\
\hline IPMN & $3072(419)$ & $226(142)$ \\
\hline PC & $4730(528)$ & $982(326)$ \\
\hline Total & $6996(657)$ & $2287(494)$ \\
\hline
\end{tabular}

CA, carcinoma; SCN, serous cystic neoplasm; MCN, mucinous cystic neoplasm; IPMN, intraductal papillary mucinous neoplasm; PC, pseudocyst.

ducts [26]. Pancreatic PCs usually communicate with pancreatic ducts, while IPMNs occupy part or the whole length of the main pancreatic duct and/or side pancreatic branches, and fluids from both cyst types are rich in amylase and other pancreatic enzymes. The cavities of both MCNs and SCNs rarely communicate with pancreatic ducts [24]. Unsurprisingly, the sensitivity of an amylase cutoff value of $250 \mathrm{UI} / \mathrm{L}$ [27] for combined PCs and IPMNs was high (97.7\%), and the specificity (62.5\%), accuracy (85.3\%), and AUC (0.945) were also relatively high.

3.2. Peptidome Analysis. LC-MS/MS analyses of the $<5 \mathrm{kDa}$ fraction from all cyst types were performed to establish a MS/MS database of the low molecular weight (LMW) peptidome fraction for further quantitative comparisons between samples. Two measurements of pooled samples were carried out for each group. The analyses yielded 411,763 fragmentation spectra, and a search against the SwissProt database using the Mascot engine identified a set of 9429 peptides (represented by 78,013 spectra), with an estimated false discovery rate (FDR) of 0.01 (Table S1). Peptides originated from 796 proteins, among which 442 were represented by at least two peptides (Table S2). Of note, $77 \%$ of proteins were present in the Plasma Proteome Database (PPD; www.plasmaproteomedatabase.org) [28], and more than $25 \%$ of identified peptides represented three blood proteins (haemoglobin, albumin, and fibrinogen) indicating extensive similarity in cyst fluid composition with the blood proteome.

Gene Ontology (GO) analysis showed a significant overrepresentation of peptidases and their inhibitors in our dataset (adj. $p \leq 0.05$ with Bonferroni correction), assigning them into five GO terms based on the molecular function category (Figure S2 and Table S3). Overall, of the 796 identified proteins there were 60 proteins belonging to the peptidase activity GO term (Table S4), and 111 were present in the MEROPS database [29] that provides information on peptidases and their inhibitors (Table S2). Although cyst fluid proteomes are very similar to the blood proteome, it is not clear whether cyst fluid peptides derived from serum proteins reflect proteolytic activity of blood, cyst fluids or both.

Peptides identified in all LC-MS/MS runs were then overlaid on the LC-MS profile data of individual samples to extract peptides' quantitative features across 8, 16, 5, 7, and 3 IPMN, PC, MCN, SCN, and CA PCL samples, respectively.
Additionally, nine UNC samples were also included in the analysis. Quantitative values were obtained for 6996 peptides originating from 657 proteins (Table S5). Of these, 6481 peptides were not found in at least one cyst type, 2287 peptides were unique to a single type, and only 515 peptides, derived from 126 proteins, were shared across all the studied cyst types. An ANOVA-based comparison identified 32 peptides originating from 12 proteins with differential (adjusted $p$ value $\leq 0.05, F C \geq 1.5$ ) abundance in at least one of the five types of PCLs (Table S6). While quantitative analysis of individual degradomes has been challenging because of their noticeable variability (Table 2 and Figure 2), at least some of the observed differences might result from uneven numbers of samples representing different cyst types.

The comparison of sequence logos depicting relative frequencies of amino acids occurring in proteins at positions surrounding the $\mathrm{N}$ - and $\mathrm{C}$-termini of the detected peptides revealed similarities for $\mathrm{CA}, \mathrm{SCN}$, and MCN groups, as well as for PC and IPMN samples, suggesting that differences in degradome composition may not only stem from primary protein abundance, but also from distinct proteolytic activity, inherent to a given cyst type (Figure 3 ). The peptide degradation patterns in $\mathrm{CA}, \mathrm{SCN}$, and $\mathrm{MCN}$ samples contained abundant shorter versions of initial peptide forms of a peptide ladder, as exemplified by alpha, beta and delta haemoglobin (Figure 4) and four other proteins (Figure S1), which comprised the top seven most abundant proteins in the degradome (Table S2).

This observation is consistent with the results of principal component analysis (PCA) of the data set. The scores of the first principal component, which captured $36 \%$ of the data variance, clearly distinguished PC and IPMN groups from CA, SCN, and MCN groups (Figure 5). Inclusion of UNC samples to the PCA analysis allowed them to be assigned to one of the supergroups. Interestingly, the differences between PC/IPMN and CA/SCN/MCN supergroups were also detectable after peptide grouping in accordance with the proteins from which they were derived. Noticeable differences in the number of peptides detected between these groups could be observed for 51 proteins (Table S7). Significantly, among these proteins the peptidases and peptidase inhibitors were present (Table 3).

3.3. Proteome Analysis. To catalogue cyst fluid proteomes for LC-MS/MS survey, we used trypsin-digested aspirated 


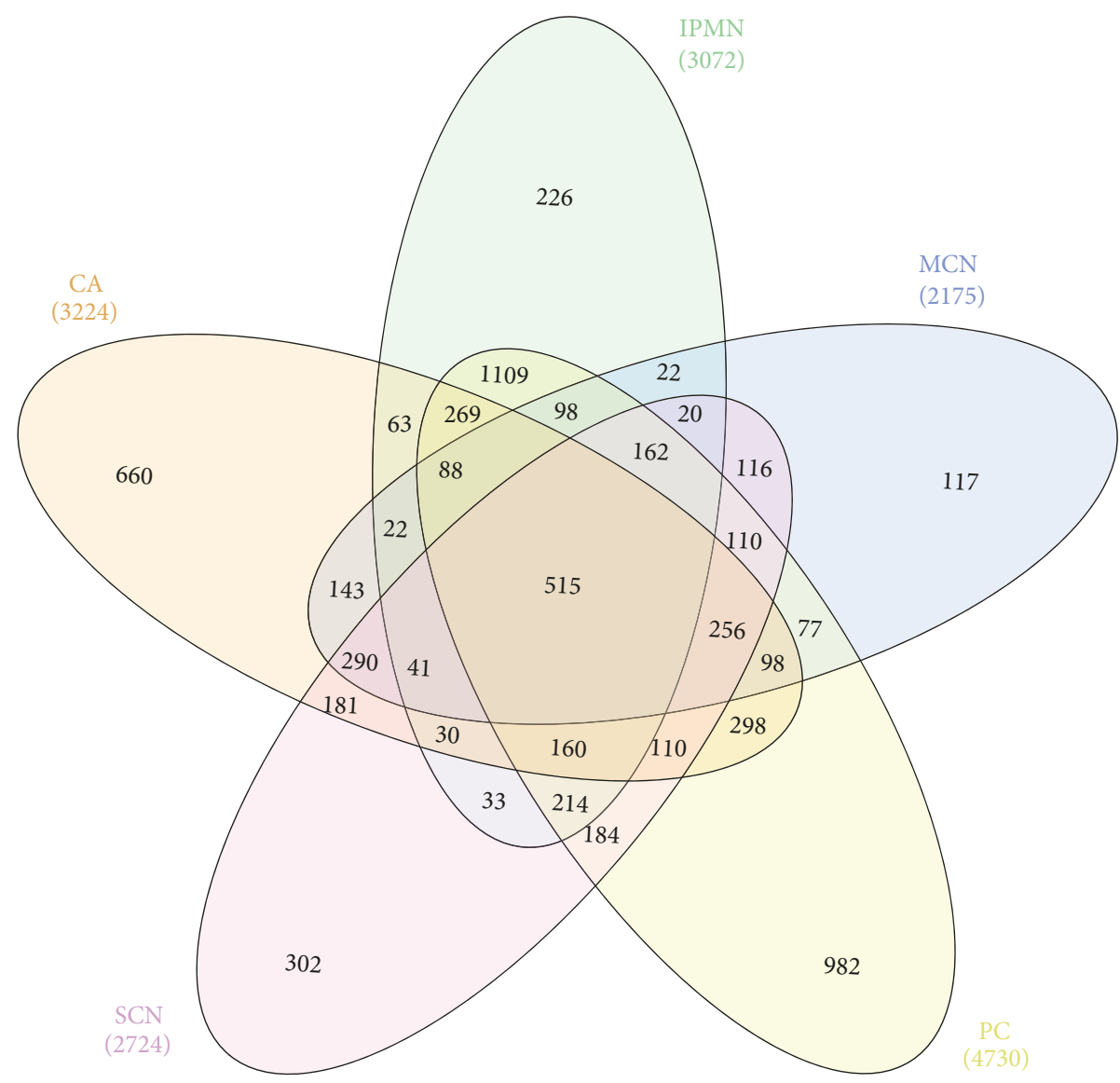

FIGURE 2: Venn diagram depicting the distribution of identified peptides in different types of pancreatic cyst lesions CA, carcinoma; SCN, serous cystic neoplasm; MCN, mucinous cystic neoplasm; IPMN, intraductal papillary mucinous neoplasm; PC, pseudocyst.
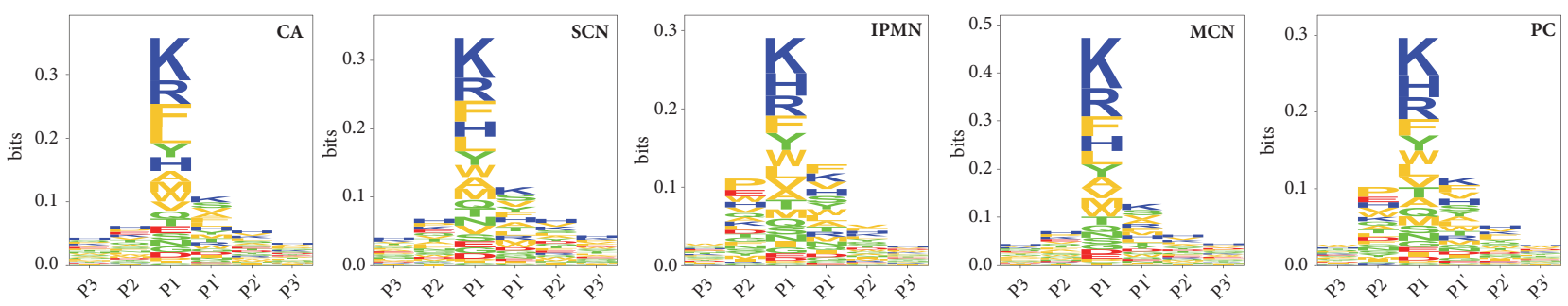

FIGURE 3: Sequence Logo plots depicting protease specificity. Positions flanking the N- and C-terminal sides of the cleavage site are named according to standard protease nomenclature, where the cleavage takes place between P1 and P1'[12]. The information content of the position is expressed in bits. Amino acids are represented in one-letter code and coloured according to their physicochemical characteristics: polar, green, hydrophobic, orange, basic, blue, acidic, red. CA, carcinoma; SCN, serous cystic neoplasm; MCN, mucinous cystic neoplasm; IPMN, intraductal papillary mucinous neoplasm; PC, pseudocyst.

samples without prior fractionation. In total 393,637 MS/MS spectra were acquired. After the database searching procedure all peptides that were also present in the $<5 \mathrm{kDa}$ dataset were excluded from further analyses. Overall, 4011 peptides (represented by 43,370 spectra) were identified and assigned to 366 proteins with at least two peptides (Tables S8 and S9). Of these, 285 proteins (78\%) were present in the PPD. Comparison of the identifications made in proteome and degradome samples revealed 239 common proteins identified by minimum two peptides, 203 unique to the $<5 \mathrm{kDa}$ fraction, and 127 found only in the proteome (Tables S2 and S9).

Of the identified proteins, 69 were present in the MEROPS database, and of these, 9 were not detected in the degradome dataset (Table S9). GO analysis of the proteome dataset revealed significant enrichment of 13 molecular function GO terms (Table S10 and Figure S3), of which five were related to the activity of proteases and their inhibitors. In total, 46 proteins were assigned to these GO terms, and 38 were also included in the MEROPS database (Table S11). 


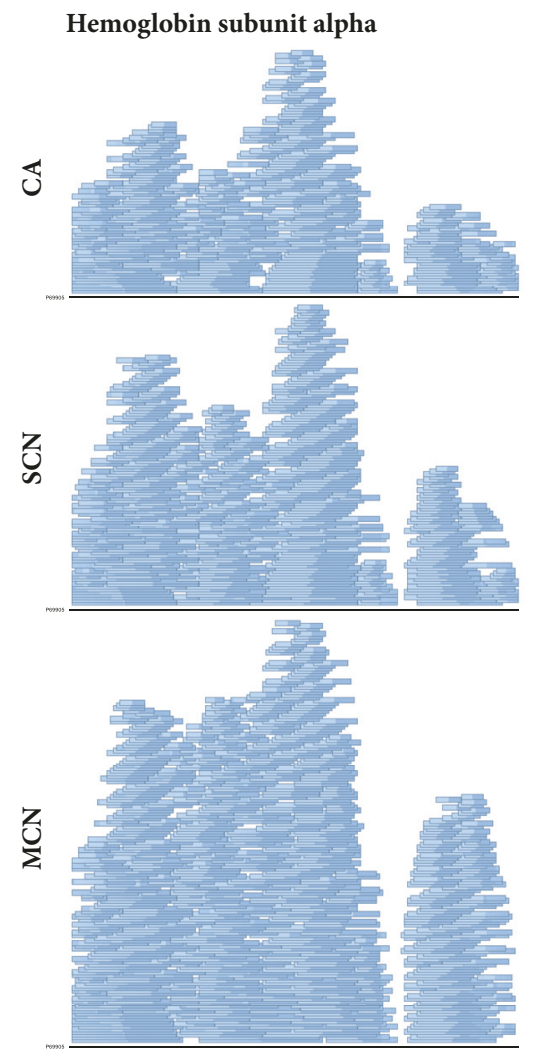

Hemoglobin subunit beta
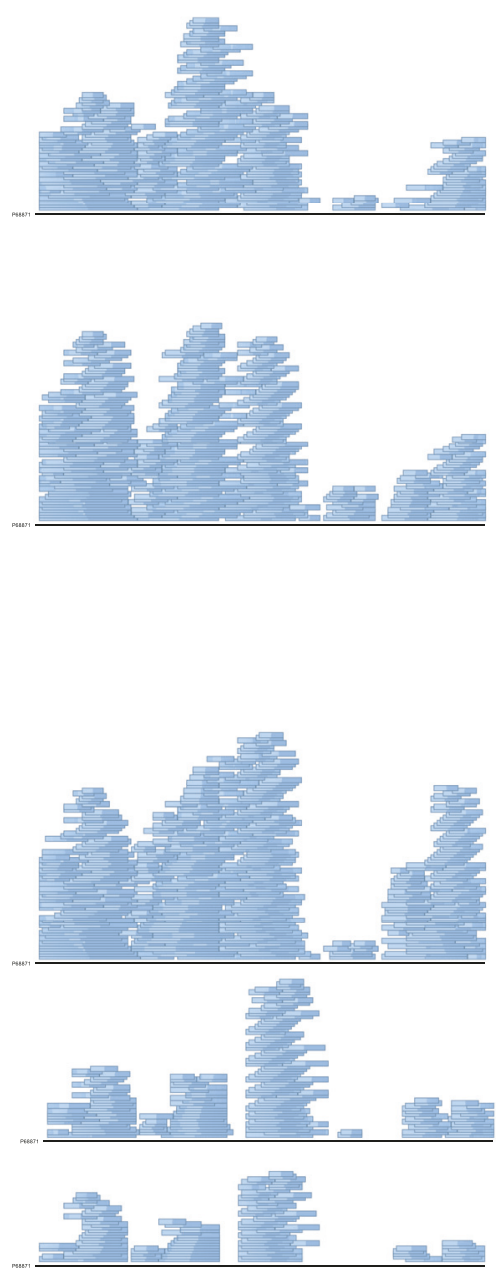

Hemoglobin subunit delta
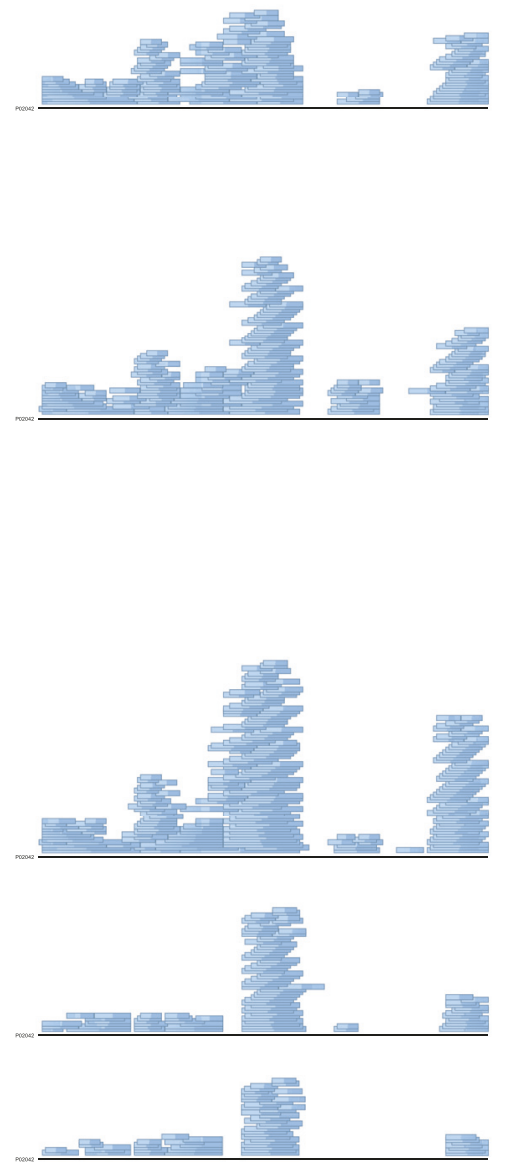

FIGURE 4: Coverage of alpha, beta and delta haemoglobin amino acid sequences in pancreatic cyst lesions. Stacked rectangles represent the distribution of identified peptides along the protein sequence. CA, carcinoma; SCN, serous cystic neoplasm; MCN, mucinous cystic neoplasm; IPMN, intraductal papillary mucinous neoplasm; PC, pseudocyst.

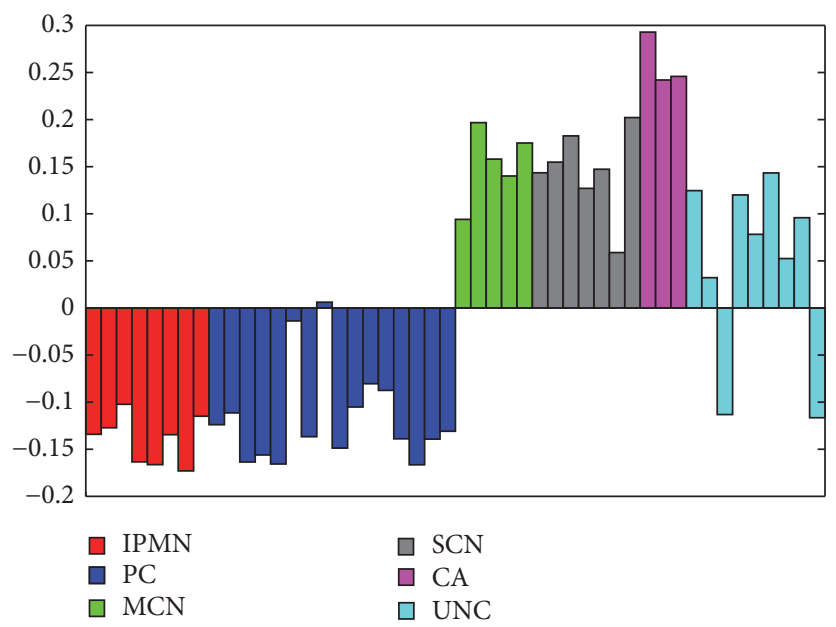

FIGURE 5: Diagram of the projection of the degradome dataset on the first principal component. IPMN, intraductal papillary mucinous neoplasm; PC, pseudocyst; MCN, mucinous cystic neoplasm; SCN, serous cystic neoplasm; CA, carcinoma. 
TABle 3: Peptidases (P) and peptidase inhibitors (I) in the degradome fraction for which a different number of peptides were identified between combined CA, MCN, and SCN versus PC and IPMN groups.

\begin{tabular}{|c|c|c|c|c|c|c|c|}
\hline UniProt ACC & Name & $\mathrm{P} / \mathrm{I}$ & IPMN & PC & $\mathrm{MCN}$ & SCN & CA \\
\hline $\mathrm{P} 15085$ & Carboxypeptidase A1 & $\mathrm{P}$ & 53 & 64 & 6 & 7 & 19 \\
\hline $\mathrm{P} 48052$ & Carboxypeptidase A2 & $\mathrm{P}$ & 11 & 14 & 0 & 1 & 3 \\
\hline $\mathrm{P} 15086$ & Carboxypeptidase B & $\mathrm{P}$ & 45 & 48 & 3 & 4 & 7 \\
\hline P08217 & Chymotrypsin-like elastase family member $2 \mathrm{~A}$ & $\mathrm{P}$ & 7 & 7 & 1 & 1 & 2 \\
\hline P08218 & Chymotrypsin-like elastase family member $2 \mathrm{~B}$ & $\mathrm{P}$ & 6 & 6 & 0 & 1 & 0 \\
\hline P09093 & Chymotrypsin-like elastase family member $3 \mathrm{~A}$ & $\mathrm{P}$ & 9 & 8 & 3 & 1 & 3 \\
\hline P08861 & Chymotrypsin-like elastase family member 3B & $\mathrm{P}$ & 5 & 5 & 1 & 1 & 2 \\
\hline P07477 & Trypsin-1 & $\mathrm{P}$ & 10 & 12 & 0 & 1 & 4 \\
\hline P07478 & Trypsin-2 & $\mathrm{P}$ & 13 & 13 & 0 & 0 & 1 \\
\hline P00738 & Haptoglobin & $\mathrm{I} / \mathrm{P}$ & 31 & 36 & 11 & 10 & 19 \\
\hline P04196 & Histidine-rich glycoprotein & $\mathrm{I}$ & 5 & 7 & 1 & 1 & 2 \\
\hline P01042 & Kininogen-1 & $\mathrm{I}$ & 3 & 3 & 10 & 6 & 9 \\
\hline Q99895 & Chymotrypsin-C & $\mathrm{P}$ & 4 & 3 & 0 & 0 & 1 \\
\hline
\end{tabular}

CA, carcinoma; SCN, serous cystic neoplasm; MCN, mucinous cystic neoplasm; IPMN, intraductal papillary mucinous neoplasm; PC, pseudocyst.

TABLE 4: Unique proteins for a given cyst type detected in proteome analysis.

\begin{tabular}{|c|c|c|c|c|c|c|}
\hline \multirow[t]{2}{*}{ UniProt ACC } & \multirow[t]{2}{*}{ Name } & \multicolumn{5}{|c|}{ Type of cyst } \\
\hline & & PC & $\mathrm{MCN}$ & SCN & CA & IPMN \\
\hline P08727 & Keratin, type I cytoskeletal 19 & & & & + & \\
\hline P07355 & Annexin A2 & & & & + & \\
\hline Q07654 & Trefoil factor 3 & & & & + & \\
\hline P04083 & Annexin A1 & & & & + & \\
\hline P55774 & C-C motif chemokine 18 & & & + & & \\
\hline $\mathrm{P} 20142$ & Gastricsin & & + & & & \\
\hline P02549 & Spectrin alpha chain, erythrocytic 1 & & + & & & \\
\hline O43707 & Alpha-actinin-4 & + & & & & \\
\hline P05783 & Keratin, type I cytoskeletal 18 & + & & & & \\
\hline P35579 & Myosin-9 & + & & & & \\
\hline P15814 & Immunoglobulin lambda-like polypeptide 1 & + & & & & \\
\hline Q04118 & Basic salivary proline-rich protein 3 & + & & & & \\
\hline P08238 & Heat shock protein HSP 90-beta & + & & & & \\
\hline Q06033 & Inter-alpha-trypsin inhibitor heavy chain $\mathrm{H} 3$ & + & & & & \\
\hline P67936 & Tropomyosin alpha-4 chain & + & & & & \\
\hline Q06323 & Proteasome activator complex subunit 1 & + & & & & \\
\hline P27352 & Gastric intrinsic factor & + & & & & \\
\hline P30046 & D-dopachrome decarboxylase & + & & & & \\
\hline O43653 & Prostate stem cell antigen & + & & & & \\
\hline
\end{tabular}

CA, carcinoma; SCN, serous cystic neoplasm; MCN, mucinous cystic neoplasm; IPMN, intraductal papillary mucinous neoplasm; PC, pseudocyst.

Proteome quantitative analysis of LC-MS data was performed for the same set of 48 fluid samples as employed in the degradome quantitative survey. Relative expression values in at least one individual sample were measured for 330 proteins (Table S12). Of these, 271, 246, 254, 214, and 290 proteins were found in CA, SCN, MCN, IPMN, and PC sample, respectively. As previously noted for the degradome, high compositional variability was also observed in the proteome data. For example, only about $2 \%$ of these proteins were detected in all individual samples quantified, and only $48 \%$ of proteins were present in at least 38 samples ( $80 \%$ of the dataset). Similarly, as in the degradome dataset, there were noticeable differences in sample composition, with only 168 (49\%) common proteins, and 19 proteins which appeared to be unique to a particular cyst type (Table 4 and Figure 6). Furthermore 143 proteins were not detected in at least one of the studied groups of samples (Table S12).

As before, the projection of the proteome dataset on the first principal component (representing $23 \%$ of total variance) distinguished PCs and IPMNs from CAs, SCNs, and 


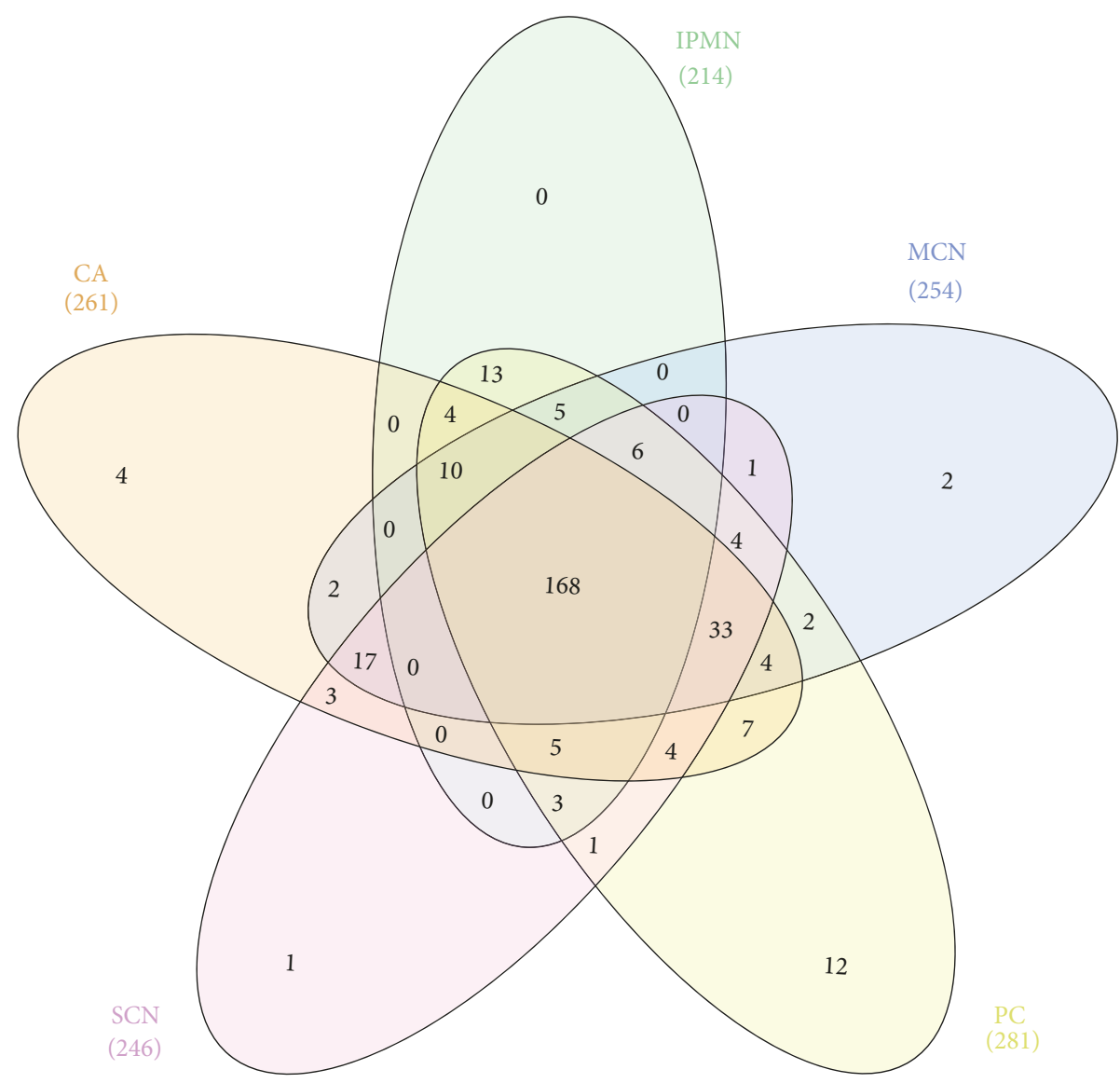

FIGURE 6: Venn diagram depicting proteome similarities in different types of pancreatic cyst lesions.

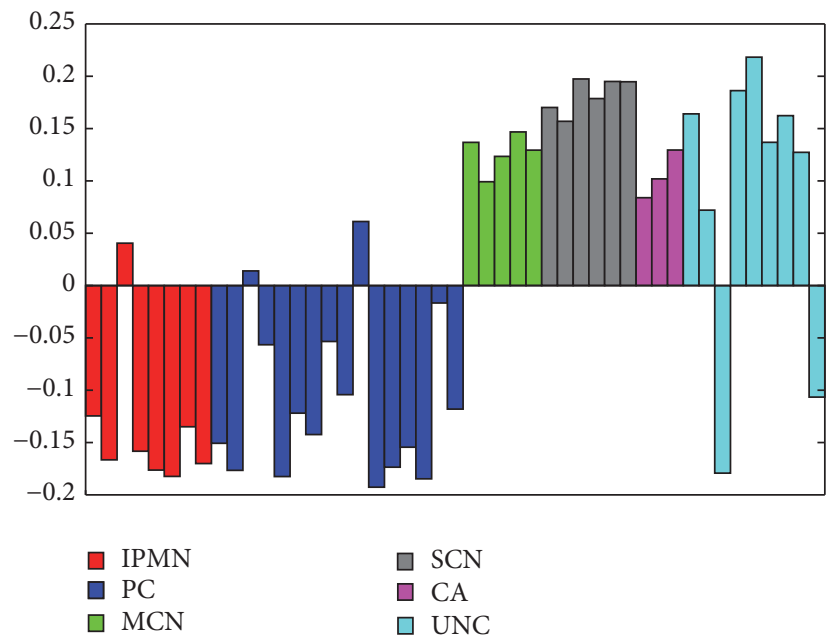

FIGURE 7: Diagram of the projection of the proteome dataset on the first principal component. IPMN, intraductal papillary mucinous neoplasm; PC, pseudocyst; MCN, mucinous cystic neoplasm; SCN, serous cystic neoplasm; CA, carcinoma; UNC, unclassified.

MCNs (Figure 7). Additionally, allocation of UNC samples was consistent for both datasets (Figures 5 and 7). A further statistical testing procedure allowed for the selection of 33 proteins with significantly (adjusted $p$-value $\leq 0.05, \mathrm{FC} \geq 1.5$ ) altered abundance in at least one of the studied groups (Table S13). Interestingly, 16 of the selected proteins possessed proteolytic activity according to the MEROPS database (Table S13). 


\section{Discussion}

Although the concept of the peptidome and degradome has been used interchangeably, the degradome refers to the LMW fraction of the plasma/serum proteome dominated by the same endogenous peptides but shortened by one or more amino acids at the $\mathrm{N}$ - and/or C-termini [14, 30, 31]. The composition of the blood degradome may vary between normal and diseased phenotypes as a result of the activity of more than 500 proteases responsible for protein degradation [30]. Similarly, the presence or absence of a set of peptides in PCF, and variation in their abundance, can indicate ongoing pathologies and thus serve as potential biomarkers for the diagnosis or prognosis of pancreatic cysts.

The present study confirmed the previously published proteomic analyses of PCFs by Ke and coworkers [8] by showing that PCFs are dominated by blood proteins $(80 \%$ of all identified proteins are constituents of the blood proteome), and a high proportion of identified proteins possess proteolytic activity. As a consequence, the LMW fraction of PCFs is mostly composed of proteolytic fragments of blood proteins. Contrary to the previous statement that complexity of the PCF degradome due to the presence of multiple proteases makes analysis overly challenging the differences in peptide abundance allowed us to discriminate two groups of PCFs, one comprising $\mathrm{CA}, \mathrm{SCN}$ and $\mathrm{MCN}$, and the other containing PC and IPMN cysts. Importantly, similarly to quantitative proteome experiments, measuring peptide levels in the degradome enabled classification of previously undiagnosed cysts into one of the groups. This was presumably possible due to the large number of different cyst types included in this study, compared with the number included in the study by Ke and colleagues who investigated PCFs from only 20 patients.

It should be noted that differences in the degradome composition are not directly transferable to differences in a given protein presence and its relative levels. As shown in Table 2, 2287 peptides unique for one of the cyst groups, which represented $35 \%$ of peptides subjected to quantitative analyses, derived from 496 proteins, represented $75 \%$ of identified proteins. Whereas peptide patterns from the given protein may be unique for a cyst type as a result of differences in cystic fluid proteolytic activity, at least to some extent, the protein itself may not be longer unique and can occur in various cyst types (Table S5). In fact, only 12, 2, 1, 4, and none proteins were unique for $\mathrm{PC}, \mathrm{MCN}, \mathrm{SCN}, \mathrm{CA}$, and IPMN PCFs, respectively (Table 4), and can be considered as protein markers for a given cyst type. Interestingly, some of these proteins have already been connected with pancreas biology and even proposed as potential cancer biomarkers. For example Annexin A2 (ANXA2), found in CA samples only, has been shown as aberrantly expressed in a wide spectrum of tumours, functionally playing an important role in tumour growth and progression [32]. In pancreatic cancer patient's high stromal ANXA2 level was predictive for reduced disease-free survival and overall survival [33]. The Gastricsin, in proteome dataset unique for MCN samples, has been shown as overexpressed in PCLs [34] and measurement of its activity was recently proposed as a biomarker for differentiating mucinous from nonmucinous PCLs [35]. In the PC samples we found 12 specific proteins, of them Alphaactinin-4 (ACTN4), Keratin 18, Myosin-9, and Tropomyosin alpha- 4 chain are constituents of cells' cytoskeleton. The ACTN4 expression was found in Langerhans islets at the mRNA and protein level [36]; another study reported this protein as being secreted by pancreatic cancer stem cells [37].

This is the first study comparing degradome and proteome from different types of PCFs. Although degradomecentred studies of bodily fluids are under-represented in the scientific literature compared with proteome-focused studies, exploration of endogenous, native peptides under pathogenic conditions may identify specific peptides and/or differences in their abundance that could serve as biomarkers for the diagnosis or prognosis of the disease [38]. However, the uncontrollable proteolytic activity in PCFs leads to serious methodological limitations for the use of PCF protein-based tests in clinical practice. The dominance of blood proteins in PCF samples combined with the presence of peptidases can hinder the correct identification and quantification of proteins and the effective classification of potential biomarkers when commonly used statistical methods such as unsupervised hierarchical clustering and principal component analysis are employed $[39,40]$. In addition, preanalytical factors including sample collection and processing may influence PCF protein levels and composition. Indeed, in amylase-rich cyst fluids, we found noticeably fewer unique peptides and proteins, and in general, the higher the proteolytic activity in PCF, the lower the levels of intact proteins. Since we did not directly measure the enzymatic activity in cyst fluids, we can only speculate that the observed differences within the peptidome and degradome of different cyst types not only stem from variation in primary protein abundance, but may also reflect inherent and ex vivo proteolytic activity within a given cyst type. Unfortunately, it is not yet possible to conclude whether the cyst fluid degradome reflects proteolytic activity of pancreatic enzymes, blood proteases, or both. Additionally, future comparative experiments with the inclusion of protease inhibitors upon PCF harvesting are warranted to dissect the extent of intrinsic and ex vivo proteolytic activity impact on PCF proteome and degradome composition.

\section{Conclusions}

While ex vivo proteolytic activity can be controlled by the inclusion of protease inhibitors during sample collection, in vivo protein nicking in cyst fluids may not be preventable [8]. Nevertheless, we believe that peptidase-driven peptide degradation patterns could be employed for yet unexplored diagnostic purposes, opening a new avenue for investigating PCFs. Despite improvements, biomarker validation remains a challenging and time- and resource-consuming task, requiring careful consideration to reduce the number of false positive identifications during the exploratory stages of research employing mass spectrometric methods. Since no consensus has yet been developed on appropriate methods for handling and processing PCFs, similar to the difficulties encountered in the Human Plasma Proteome Project [41, 42], 
establishing new endogenous peptide-based biomarkers will need careful verification by alternative methods conducted on a large number of samples.

\section{Data Availability}

Mass spectrometry proteomics data have been deposited at the ProteomeXchange Consortium via the PRIDE [43] partner repository with the dataset identifiers PXD005248 and 10.6019/PXD005248.

\section{Conflicts of Interest}

The authors declare that they have no conflicts of interest.

\section{Authors' Contributions}

Agnieszka Paziewska and Marcin Polkowski equally contributed.

\section{Acknowledgments}

We thank Krzysztof Goryca for his assistance with statistical analyses of fluid amylase and CEA datasets. This work was supported by the National Science Centre [2012/05/B/NZ5/01539].

\section{Supplementary Materials}

Figure S1: coverage of serum albumin, fibrinogen alpha chain, apolipoprotein A-I, and alpha-1-antitrypsin in pancreatic cyst fluids. CA, carcinoma; SCN, serous cystic neoplasm; MCN, mucinous cystic neoplasm; IPMN, intraductal papillary mucinous neoplasm; PC, pseudocyst. Figure S2: dendrogram of significantly enriched (red) GO terms in the degradome dataset. Figure S3: dendrogram of significantly enriched (red) GO terms in the proteome dataset. Supplementary Tables $\mathbf{1}-13$ are deposited in separate excel file. (Supplementary Materials)

\section{References}

[1] O. Basturk, I. Coban, and N. V. Adsay, "Pancreatic cysts: pathologic classification, differential diagnosis, and clinical implications," Arch. Pathol. Lab. Med, vol. 133, no. 3, pp. 423438, 2009.

[2] A. V. Maker, N. Katabi, L.-X. Qin et al., "Cyst fluid interleukin$1 \beta$ (IL1 $\beta$ ) levels predict the risk of carcinoma in intraductal papillary mucinous neoplasms of the pancreas," Clinical Cancer Research, vol. 17, no. 6, pp. 1502-1508, 2011.

[3] R. M. Walsh, J. M. Henderson, D. P. Vogt et al., "Prospective preoperative determination of mucinous pancreatic cystic neoplasms," Surgery, vol. 132, no. 4, pp. 628-634, 2002.

[4] L. A. van der Waaij, H. M. van Dullemen, and R. J. Porte, "Cyst fluid analysis in the differential diagnosis of pancreatic cystic lesions: a pooled analysis," Gastrointestinal Endoscopy, vol. 62, no. 3, pp. 383-389, 2005.
[5] H.-C. Oh, M.-H. Kim, C. Y. Hwang et al., "Cystic lesions of the pancreas: Challenging issues in clinical practice," American Journal of Gastroenterology, vol. 103, no. 1, pp. 229-239, 2008.

[6] N. Thiruvengadam and W. G. Park, "Systematic Review of Pancreatic Cyst Fluid Biomarkers: The Path Forward," Clinical and Translational Gastroenterology, vol. 6, no. 6, pp. e88-e88, 2015.

[7] A. Cuoghi, A. Farina, K. Z'graggen et al., "Role of proteomics to differentiate between benign and potentially malignant pancreatic cysts," Journal of Proteome Research, vol. 10, no. 5, pp. 2664-2670, 2011.

[8] E. Ke, B. B. Patel, T. Liu et al., "Proteomic Analyses of Pancreatic Cyst Fluids," Pancreas, vol. 38, no. 2, pp. e33-e42, 2009.

[9] B. B. Haab, A. Porter, T. Yue et al., "Glycosylation variants of mucins and CEACAMs as candidate biomarkers for the diagnosis of pancreatic cystic neoplasms," Annals of Surgery, vol. 251, no. 5, pp. 937-945, 2010.

[10] Z. Cao, K. Maupin, B. Curnutte et al., "Specific glycoforms of MUC5AC and endorepellin accurately distinguish mucinous from nonmucinous pancreatic cysts," Molecular \& Cellular Proteomics, vol. 12, no. 10, pp. 2724-2734, 2013.

[11] C. J. DiMaio, F. Weis-Garcia, E. Bagiella, L. H. Tang, and P. J. Allen, "Pancreatic cyst fluid concentration of high-mobility group A2 protein acts as a differential biomarker of dysplasia in intraductal papillary mucinous neoplasm," Gastrointestinal Endoscopy, vol. 83, no. 6, pp. 1205-1209, 2016.

[12] I. Schechter and A. Berger, "On the size of the active site in proteases. I. Papain," Biochemical and Biophysical Research Communications, vol. 27, no. 2, pp. 157-162, 1967.

[13] M. Polkowski, A. Larghi, B. Weynand et al., "Learning, techniques, and complications of endoscopic ultrasound (EUS)-guided sampling in gastroenterology: European Society of Gastrointestinal Endoscopy (ESGE) Technical Guideline," Endoscopy, vol. 44, no. 2, pp. 190-205, 2012.

[14] M. Bakun, J. Karczmarski, J. Poznanski et al., "An integrated LC-ESI-MS platform for quantitation of serum peptide ladders. Application for colon carcinoma study," Proteomics - Clinical Applications, vol. 3, no. 8, pp. 932-946, 2009.

[15] M. Mikula, T. Rubel, J. Karczmarski, M. Statkiewicz, K. Bomsztyk, and J. Ostrowski, "Beads-free protein immunoprecipitation for a mass spectrometry-based interactome and posttranslational modifications analysis," Proteome Science, vol. 13, no. 1, 2015.

[16] L. Käll, J. D. Storey, M. J. MacCoss, and W. S. Noble, “Assigning significance to peptides identified by tandem mass spectrometry using decoy databases," Journal of Proteome Research, vol. 7, no. 1, pp. 29-34, 2008.

[17] M. Mikula, P. Gaj, K. Dzwonek et al., "Comprehensive analysis of the palindromic motif TCTCGCGAGA: A regulatory element of the HNRNPK promoter," DNA Research, vol. 17, no. 4, pp. 245-260, 2010.

[18] T. D. Schneider and R. M. Stephens, "Sequence logos: A new way to display consensus sequences," Nucleic Acids Research, vol. 18, no. 20 , pp. 6097-6100, 1990.

[19] W. S. Cleveland and S. J. Devlin, "Locally weighted regression: an approach to regression analysis by local fitting," Journal of the American Statistical Association, vol. 83, no. 403, pp. 596$610,1988$.

[20] T. Välikangas, T. Suomi, and L. L. Elo, "A systematic evaluation of normalization methods in quantitative label-free proteomics," Briefings in Bioinformatics, vol. 19, no. 1, pp. 1-11, 2018. 
[21] Y. Benjamini and Y. Hochberg, "Controlling the false discovery rate: a practical and powerful approach to multiple testing," Journal of the Royal Statistical Society B: Methodological, vol. 57, no. 1, pp. 289-300, 1995.

[22] H. Mi, S. Poudel, A. Muruganujan, J. T. Casagrande, and P. D. Thomas, "PANTHER version 10: expanded protein families and functions, and analysis tools," Nucleic Acids Research, vol. 44, no. D1, pp. D336-D342, 2016.

[23] J. Park, H. S. Yun, K. H. Lee, K. T. Lee, J. K. Lee, and S.-Y. Lee, "Discovery and validation of biomarkers that distinguish mucinous and nonmucinous pancreatic cysts," Cancer Research, vol. 75, no. 16, pp. 3227-3235, 2015.

[24] I. Karoumpalis and D. K. Christodoulou, "Cystic lesions of the pancreas," Annals of Gastroenterology, vol. 29, no. 2, pp. 155-161, 2016.

[25] A. Kadayifci, M. Al-Haddad, M. Atar et al., "The value of KRAS mutation testing with CEA for the diagnosis of pancreatic mucinous cysts," Endoscopy International Open, vol. 4, no. 4, pp. E391-E396, 2016.

[26] P. Hammel, P. Levy, H. Voitot et al., "Preoperative cyst fluid analysis is useful for the differential diagnosis of cystic lesions of the pancreas," Gastroenterology, vol. 108, no. 4, pp. 1230-1235, 1995.

[27] G. A. Ketwaroo, K. J. Mortele, and M. S. Sawhney, "Pancreatic Cystic Neoplasms: An Update," Gastroenterology Clinics of North America, vol. 45, no. 1, pp. 67-81, 2016.

[28] B. Muthusamy, G. Hanumanthu, S. Suresh et al., "Plasma proteome database as a resource for proteomics research," Proteomics, vol. 5, no. 13, pp. 3531-3536, 2005.

[29] N. D. Rawlings, A. J. Barrett, and A. Bateman, "MEROPS: the database of proteolytic enzymes, their substrates and inhibitors," Nucleic Acids Research, vol. 40, no. 1, pp. D343D350, 2012.

[30] Y. Shen, T. Liu, N. Tolić et al., "Strategy for degradomicpeptidomic analysis of human blood plasma," Journal of Proteome Research, vol. 9, no. 5, pp. 2339-2346, 2010.

[31] J. Karczmarski, T. Rubel, M. Mikula et al., "Pre-analyticalrelated variability influencing serum peptide profiles demonstrated in a mass spectrometry-based search for colorectal and prostate cancer biomarkers," Acta Biochimica Polonica, vol. 60, no. 3, pp. 417-425, 2013.

[32] X. H. Xu, W. Pan, L. Kang, H. Feng, and Y. Song, "Association of annexin A2 with cancer development (review)," Oncology Reports, vol. 33, no. 5, pp. 2121-2128, 2015.

[33] A. G. Murphy, K. Foley, A. A. Rucki et al., "Stromal Annexin A2 expression is predictive of decreased survival in pancreatic cancer," Oncotarget, vol. 8, no. 63, pp. 106405-106414, 2017.

[34] N. B. Prasad, A. V. Biankin, N. Fukushima et al., "Gene expression profiles in pancreatic intraepithelial neoplasia reflect the effects of Hedgehog signaling on pancreatic ductal epithelial cells," Cancer Research, vol. 65, no. 5, pp. 1619-1626, 2005.

[35] S. L. Ivry, J. M. Sharib, D. A. Dominguez et al., "Global protease activity profiling provides differential diagnosis of pancreatic cysts," Clinical Cancer Research, vol. 23, no. 16, pp. 4865-4874, 2017.

[36] J. Rinta-Valkama, T. Palmén, M. Lassila, and H. Holthöfer, "Podocyte-associated proteins FAT, alpha-actinin-4 and filtrin are expressed in Langerhans islets of the pancreas," Molecular and Cellular Biochemistry, vol. 294, no. 1-2, pp. 117-125, 2007.

[37] J. Brandi, E. D. Pozza, I. Dando et al., "Secretome protein signature of human pancreatic cancer stem-like cells," Journal of Proteomics, vol. 136, pp. 1-12, 2016.
[38] C. Martelli, F. Iavarone, F. Vincenzoni et al., “Top-down peptidomics of bodily fluids," Peptidomics, vol. 1, no. 1, 2014.

[39] M. B. Eisen, P. T. Spellman, P. O. Brown, and D. Botstein, "Cluster analysis and display of genome-wide expression patterns," Proceedings of the National Acadamy of Sciences of the United States of America, vol. 95, no. 25, pp. 14863-14868, 1998.

[40] L. E. Peterson, "Partitioning large-sample microarray-based gene expression profiles using principal components analysis," Computer Methods and Programs in Biomedicine, vol. 70, no. 2, pp. 107-119, 2003.

[41] H. Tammen, I. Schulte, R. Hess et al., "Peptidomic analysis of human blood specimens: Comparison between plasma specimens and serum by differential peptide display," Proteomics, vol. 5, no. 13, pp. 3414-3422, 2005.

[42] H. Tammen and R. Hess, "Collection and handling of blood specimens for peptidomics," Methods in Molecular Biology, vol. 728, pp. 151-159, 2011.

[43] J. A. Vizcaíno, A. Csordas, N. Del-Toro et al., "2016 update of the PRIDE database and its related tools," Nucleic Acids Research, vol. 44, no. 1, pp. D447-D456, 2016. 


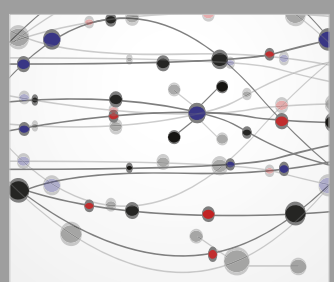

The Scientific World Journal
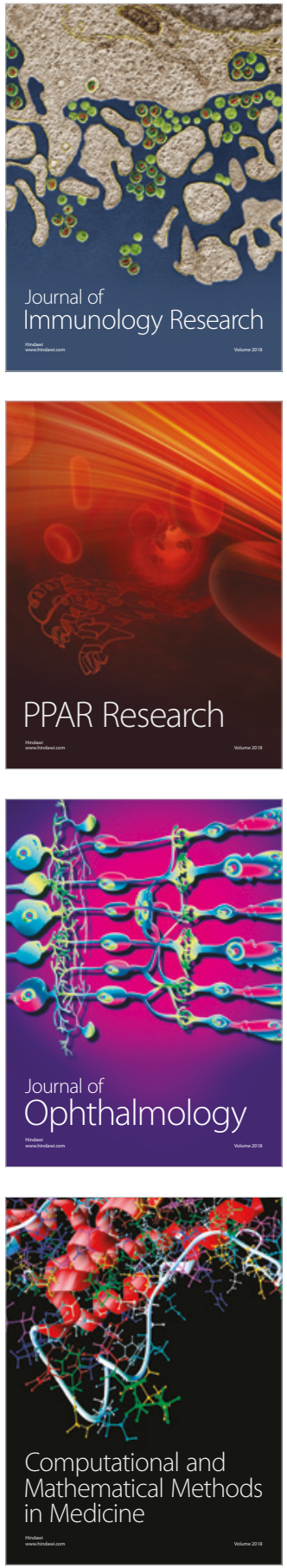

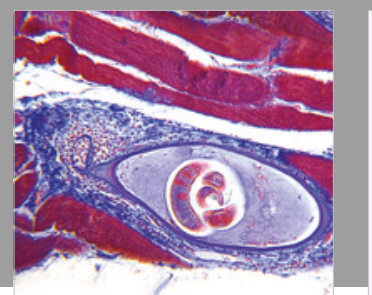

Gastroenterology Research and Practice

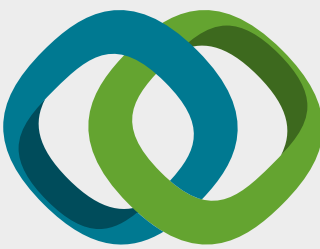

\section{Hindawi}

Submit your manuscripts at

www.hindawi.com
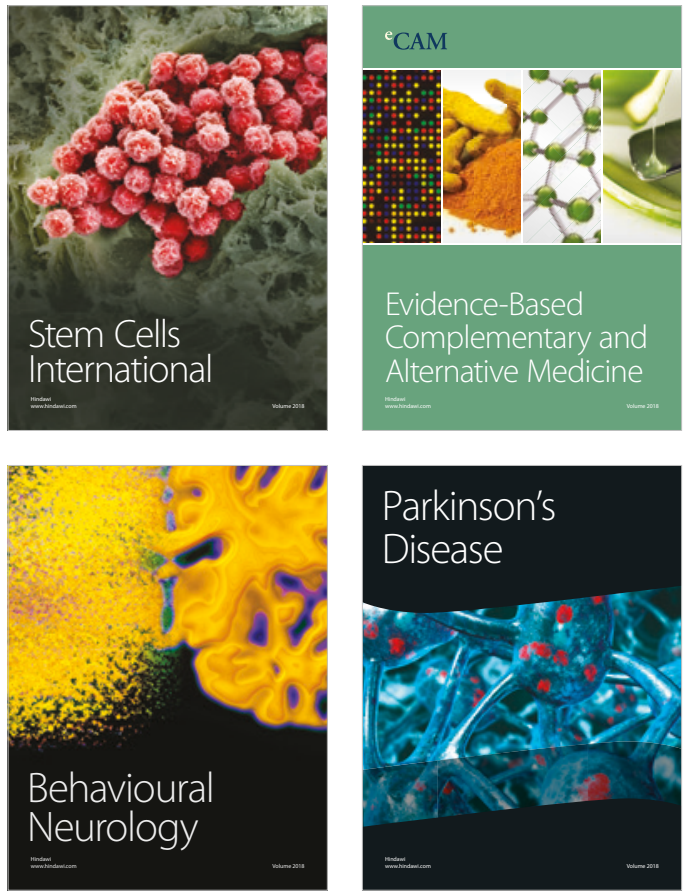

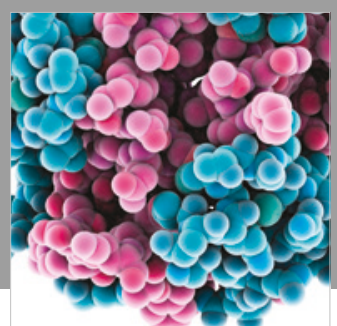

ournal of

Diabetes Research

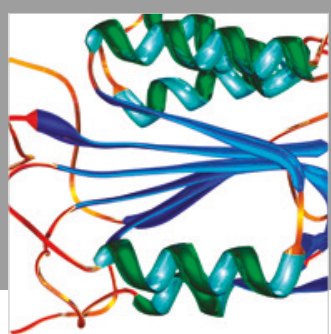

Disease Markers
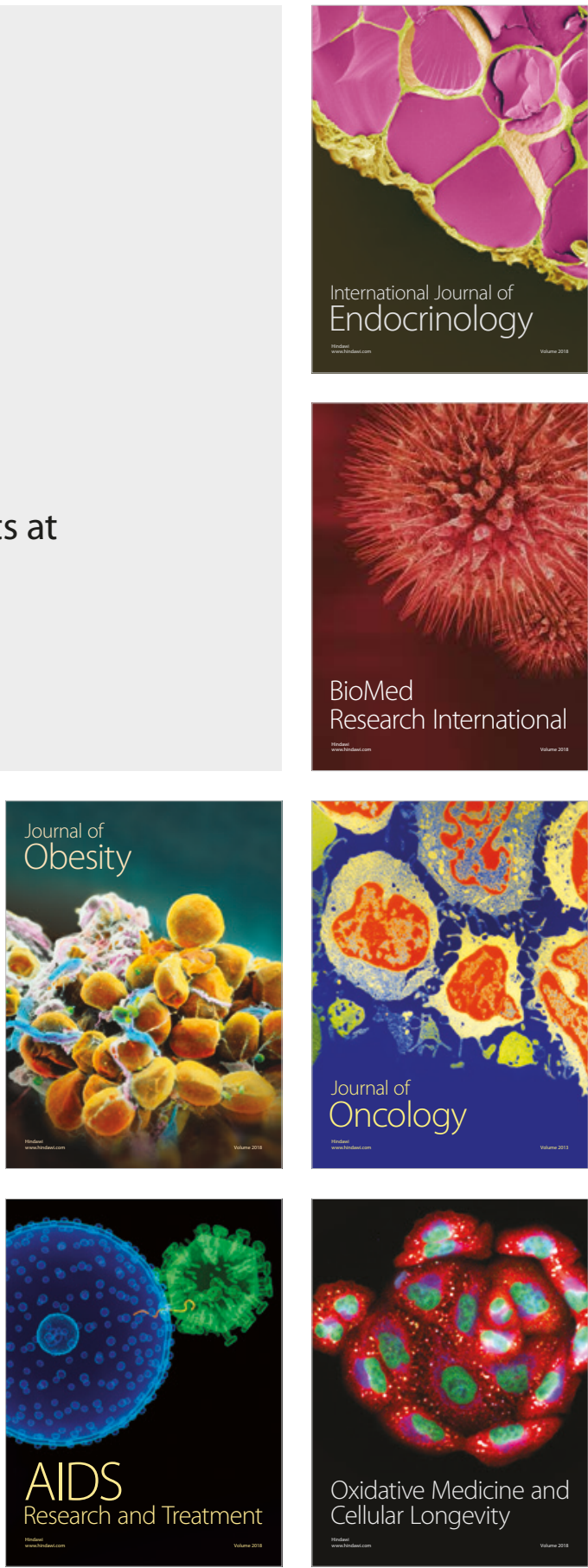